\section{Atypical pattern of (meth)acrylate allergic contact dermatitis in dental professionals}

\author{
R. Y. Prasad Hunasehally, ${ }^{1}$ T. M. Hughes ${ }^{2}$ and N. M. Stone ${ }^{3}$
}
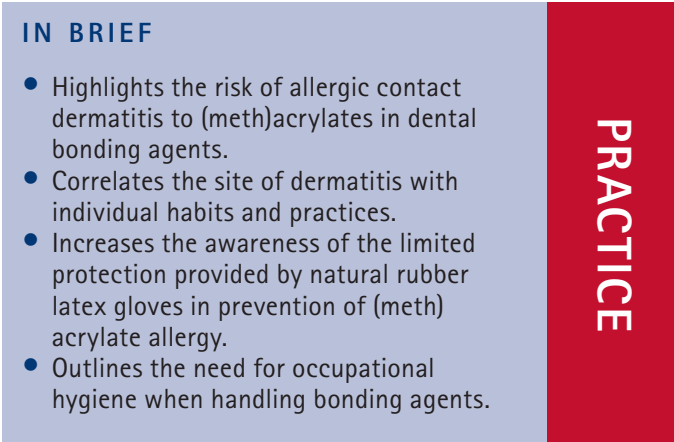

(Meth)acrylates in dental bonding agents are a common source of allergic contact dermatitis in dental professionals. The distribution of the contact dermatitis is commonly on finger tips, but is determined by individual habits as demonstrated by the two case reports in this article. Despite the site of contact dermatitis, the bonding agents are often not suspected as a source of contact allergy due to misconception regarding the protective effect of natural rubber latex gloves. With these case reports, we endeavour to emphasize the inadequacy of the latex gloves in protecting against the (meth)acrylate induced contact allergy and also list the measures a dental professional needs to incorporate in order to minimise the risks of sensitisation to (meth)acrylates.

\section{INTRODUCTION}

Dental professionals are at high risk of hand dermatitis from frequent hand washing, exposure to irritants and allergens and use of gloves. (Meth)acrylates are a recognised cause of allergic contact dermatitis (ACD) in dental personnel affecting an estimated $5 \%$ to $10 \% .^{1}$ The distribution of (meth)acrylate ACD has been reported to typically affect the finger tips/pulps as a result of dextrous handling of relevant materials. ${ }^{2,3}$ We report two cases of (meth) acrylate ACD in dental professionals, where the pattern of the dermatitis was not typical. Further history concerning individual working habits provided a clear explanation for this distribution.

Dental professionals need to be fully aware of the risks of handling materials containing (meth)acrylates and in particular the limited protection that natural rubber latex (NRL) gloves provide from these potential allergens. This fact is highlighted by the two case reports in this article and with these reports, we try to raise the

${ }^{*}$ Department of Dermatology, Princess of Wales Hospital, Bridgend, CF31 1RQ; ${ }^{2-3}$ Department of Dermatology, Royal Gwent Hospital, Newport, NP20 4SZ

${ }^{*}$ Correspondence to: Dr. R. Y. Prasad Hunasehally

Email: Prasad.hunasehally@wales.nhs.uk;

Tel: +441656752106

\section{Refereed Paper}

Accepted 12 June 2012

DOI: 10.1038/sj.bdj.2012.776

${ }^{\circledR}$ British Dental Journal 2012; 213: 223-224 awareness of protective measures to minimise the risk of ACD to (meth)acrylates.

\section{CASE REPORTS}

\section{Case one}

A 43-year-old orthodontic nurse presented with a three month history of an eczematous rash on the dorsum of the left hand, overlying the area between the first and second metacarpals. She had no lesions on the finger tips or elsewhere. She was right-handed and had a personal and family history of atopy.

She was patch-tested with the British Contact Dermatitis Society (BCDS) standard series, and a departmental medicaments, fragrance and dental/(meth)acrylate series (Chemotechnique Diagnostics, Modemgatan, Sweden). The patches were applied to the back using Finn chambers ${ }^{\oplus}$ on Scanpore tape (Vitaflo Scandinavia $\mathrm{AB}$, Goteborg, Sweden). Readings were taken according to the International Contact Dermatitis Research Group criteria. ${ }^{4}$ The only positive reaction was to 2-hydroxyethyl methacrylate (HEMA) 2\%. A skin prick test to natural rubber latex (NRL) was negative.

Her work as an orthodontic nurse involved contact with (meth)acrylate dental bonding agents. She would routinely wear NRL gloves. She described habitually wiping off excess bonding agent from a brush held in

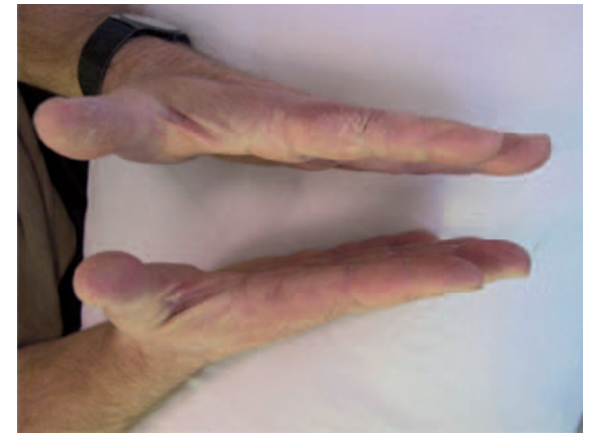

Fig. 1 Hyperkeratotic erythematous plaques over the lateral surface of the left index finger and pulp of the left thumb (Case 2)

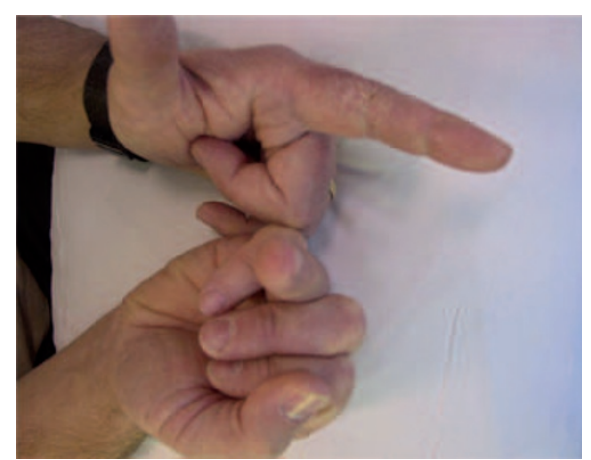

Fig. 2 Hyperkeratotic erythematous plaques over the lateral surface of the left index finger and tip of right ring finger (Case 2)

her dominant right hand, onto the dorsum of the gloved left hand, while assisting the dentist. The area of contact dermatitis correlated to the site on the left hand where she wiped off the excess bonding agent. The patch testing confirmed a diagnosis of occupational ACD to (meth)acrylate in the dental bonding material. When she stopped 
her habit of wiping bonding agent onto her hand the eczema cleared.

\section{Case two}

A 38-year-old dentist presented to the patch test clinic with a nine month history of hand dermatitis. The dermatitis improved spontaneously while he was away from work and recurred within a few days of returning. Examination revealed erythematous plaques down the lateral surface of the left index finger with hyperkeratosis and fissuring over the pulp of the left thumb and on the tip of the right ring finger (Figs 1 and 2). He had no rash elsewhere.

He was patch-tested as above with the BCDS standard series and departmental medicaments, plastics and glues and dental/(meth)acrylate series. Positive results to 2-hydroxyethyl methacrylate (HEMA) 2\%, 2-hydroxypropyl methacrylate (HPMA) 2\% and ethyleneglycol dimethacrylate(EGDMA) 2\% were found. A skin prick test to NRL was negative.

His work involved dental restoration procedures during which he routinely wore NRL gloves. On further questioning, he described a habit of using the right ring finger as an anchor against the tooth while drilling with his dominant right hand. He would wipe off excess restorative materials onto the side of his left index finger and thumb. This correlated exactly with the sites of the contact dermatitis. The positive patch tests confirmed the diagnosis of occupational ACD to (meth)acrylates in the dental restorative materials that he used. He was unaware of the short breakthrough time of (meth)acrylates when wearing NRL gloves. His eczema resolved after altering his glove technique and ceasing to wipe excess bonding agent onto his left hand. He has experienced episodes of hand eczema since that time.

\section{DISCUSSION}

Safety data sheets for dental materials are known to often be inaccurate or incomplete with regard to citing precisely which (meth) acrylates are included. Cross sensitisation between (meth)acrylates appears to be common, due to similarity in chemical structure. Concomitant sensitisations may also occur. ${ }^{5,6}$ A positive patch test to a (meth)acrylate, when dealing with materials known to contain this group of chemicals, should be sufficient to make a diagnosis of ACD.
Meth(acrylates) are a recognised cause of ACD in dental personnel. The irritancy of these chemicals can also be an important co-factor in producing hand dermatitis. ${ }^{6}$ (Meth)acrylate ACD in dental professionals mainly manifests as hand eczema, though there are also case reports of airborne ACD affecting the face. ${ }^{2,7}$ The commonest site of ACD in dental personnel has been reported to be the finger tips. In one study 93\% of contact dermatitis was distributed on the finger tips: however, involvement of the lateral aspect of fingers was almost as common. The backs of the hands were reported to be affected in about half of the cases. ${ }^{6}$ The pattern of dermatitis involvement in (meth)acrylate ACD has, as far as we are aware, not been explained other than when the finger tips are affected from dextrous contact.

In this report of (meth)acrylate ACD in two dental professionals, we draw attention to two observations. First, the unusual distribution of the dermatitis, which can be explained by their individual habits and practices when handling (meth)acrylate materials during the course of their work. Patient one had unilateral involvement of the dorsum of the left hand between the first and second metacarpal, with no dermatitis elsewhere, explained by her practice of wiping of the excess bonding agent onto dorsum of the left hand. Patient two had an asymmetrical involvement concerning the pulp of left thumb, lateral surface of the left index finger and the tip of the right ring finger. This was explained by his practice of wiping off the excess bonding agent onto his left hand and also having his right ring finger tip in contact with the patient's tooth as a support while using the dental drill.

Secondly, we emphasise that both these patients did not make a connection between the dermatitis and the (meth) acrylate material being used, even though the dermatitis appeared at the exact site of skin contact. They assumed that using NRL gloves provided protection against direct contact with such materials. It is well recognised, however, that NRL gloves provide poor protection against (meth)acrylates, with breakthrough times down to several minutes only. Nitrile gloves provide better protection than NRL or vinyl gloves. ${ }^{89}$ Also thicker gloves would provide better protection, but this obviously impacts negatively on dextrous functioning. Using a doublegloving technique, possibly with nitrile undergloves, breakthrough time should be significantly lengthened. ${ }^{8,9}$ Other basic occupational hygiene measures to protect against sensitisation would be to practice a no-touch technique, to change gloves as soon as possible after any visible contamination and to wash the skin with soap and water as soon as there is any relevant skin contact with the (meth)acrylate.

\section{CONCLUSION}

We report atypical skin presentations of (meth)acrylate ACD in two dental professionals where the distribution of dermatitis was related to their individual habits and practise while working with the relevant dental bonding materials. Such work habits may be commonly undertaken. Dental professionals should be aware of the need to prevent skin contact with (meth) acrylates and, in particular, to avoid wiping any excess onto their gloves. When using such materials, the limited protection from wearing NRL gloves may result in a false reassurance against developing ACD to the (meth)acrylate materials. Use of double-gloving technique and other basic occupational hygiene measures as mentioned above should minimise the risk of (meth)acrylate ACD.

1. Sanchez-Perez J, Gonzalez-Arriba A, Goiriz R, Garcia-Diez A. Occupational allergic contact dermatitis to acrylates and methacrylates. Contact Dermatitis 2008: 58: 252-254.

2. Guerra L, Vincenzi C, Peluso M, Tosti A. Prevalence and sources of occupational contact sensitization to acrylates in Italy. Contact Dermatitis 1993; 28: 101-103.

3. Lee J Y, Yoo J M, Cho B K, Kim H O. Contact dermatitis in Korean dental technicians. Contact Dermatitis 2001; 45: 13-16.

4. Fregert S. Manual of contact dermatitis: on behalf of the International Contact Dermatitis Research Group and the North American Contact Dermatitis Group. 2nd ed. Copenhagen: Munksgaard Publishers, 1981

5. Aalto-Korte K, Alanko K, Kuuliala O, Jolanki R. Methacrylate and acrylate allergy in dental personnel. Contact Dermatitis 2007; 57: 324-330.

6. Rustemeyer T, Frosch P J. Occupational skin diseases in dental laboratory technicians. (I). Clinical picture and causative factors. Contact Dermatitis 1996; 34: 125-133.

7. Wrangsjö K, Swartling C, Meding B. Occupational dermatitis in dental personnel: contact dermatitis with special reference to (meth)acrylates in 174 patients. Contact Dermatitis 2001; 45: 158-163.

8. Zwanenburg R, Jolanki R, Makela E, Estlander T. Glove selection for UV/EB curing acrylates. In Boman A, Estlander T, Wahlberg J E, Maibach H I (eds) Protective gloves for occupational use. 2nd ed. pp 287-298. Boca Raton: CRC Press, 2005.

9. Makela E, Jolanki R. Chemical permeation through disposable gloves. In Boman A, Estlander T, Wahlberg J E, Maibach H I (eds) Protective gloves for occupational use. 2nd ed. pp 299-314. Boca Raton: CRC Press, 2005. 